\title{
Produção de biomassa e óleo essencial de hortelã em hidroponia em fun- ção de nitrogênio e fósforo
}

\author{
Marco Andre A de Souza ${ }^{1}$; Osmário JL de Araujo²; Márcio A Ferreira ${ }^{3}$ Elvia Mariam LM Stark ${ }^{4}$; Manlio \\ S Fernandes ${ }^{5}$; Sonia R Souza ${ }^{5}$
}

UFRRJ, 23890-000 Seropédica-RJ; ${ }^{1}$ Mestrando Depto. Solos; ${ }^{2}$ Bolsista iniciação científica; ${ }^{3}$ Estudante graduando; ${ }^{4}$ Eng. Florestal; ${ }^{5}$ Prof. Associado; E-mail: decoerej@yahoo.com.br; soniabq@ufrrj.br.

\section{RESUMO}

Em experimento conduzido em sistema hidropônico foi avaliada a influência da nutrição mineral sobre o crescimento vegetal e a produção de óleos essenciais de Mentha piperita (hortelã). As plantas foram cultivadas em soluções nutritivas, variando os teores de $\mathrm{N}$ e P, sendo: 120 e 16; 60 e 16; 120 e 4; 60 e $4 \mathrm{mg} \mathrm{L}^{-1}$ de $\mathrm{N}$ e P para os tratamentos $1 ; 2 ; 3$ e 4 respectivamente. $\mathrm{O}$ maior rendimento em óleos essenciais ocorreu aos 29 DAT (dias após o inicio dos tratamentos) para as plantas cultivadas nas condições do tratamento 4; Em contrapartida, houve maior produção de biomassa aos 64 DAT (em todos os tratamentos). As plantas sob maiores doses de $\mathrm{N}$ apresentaram menor rendimento de óleo essencial; no entanto, houve maior ganho de biomassa. Observou-se uma diminuição gradual no rendimento de óleo essencial ao longo do ciclo da planta e uma relação inversa entre o peso de folhas e o rendimento de óleo. Os resultados deste trabalho mostram que aos 29 DAT em cultivo hidropônico as plantas de hortelã estão aptas para serem colhidas, com o objetivo de produção de óleo essencial, o que significa redução no tempo de colheita e economia no processo de produção.

Palavras-chave: Mentha piperita, sistema hidropônico, metabólitos secundários.

\begin{abstract}
Biomass and essential oil production of mint in hydroponic system as a function of nitrogen and phosphorus

An experiment was carried out, using a hydroponic system to study the effect of plant nutrition regimes on the plant growth and the production of essential oils in Mentha piperita (mint). Plants were grown in nutrient solutions with varying levels of $\mathrm{N}$ and P: 120 and 16; 60 and 16; 120 and 4; 60 and 4, $\mathrm{mg} \mathrm{L}^{-1}$ of $\mathrm{N}$ and $\mathrm{P}$ in the treatments $1 ; 2 ; 3$ and 4 respectively. Plants of the treatment 4 (29 days after starting the treatments, DAT) presented the highest production of essential oils. However, plants presented the highest biomass production at $64 \mathrm{DAT}$. The higher the $\mathrm{N}$ levels in the nutrient solution, the lower the production of essential oils. Higher $\mathrm{N}$ inputs resulted in higher total biomass. There was a negative relationship between the plant cycle and the production of essential oils. Mint plants grown in hydroponics systems can be harvested at 29 DAT for the production of essentials oils, saving time and costs of production.
\end{abstract}

Keywords: Mentha piperita, hydroponic system, secondary metabolites.

(Recebido para publicação em 06 de fevereiro de 2006; aceito em 9 de abril de 2007)

$\mathrm{A}$ tualmente, o cultivo de plantas medicinais assume importância mundial devido à demanda exercida pelas indústrias químicas, farmacêuticas, alimentícias e de cosméticos. Essa importância justifica o forte investimento em pesquisas com plantas medicinais, principalmente, na busca por novas ferramentas de investigação, determinação e síntese de produtos naturais (Di Stasi, 1996). Entretanto, tem-se estudado muito pouco os mecanismos relacionados à produção, sob os aspectos quantitativos e qualitativos, dessas substâncias, principalmente, no que concerne aos aspectos ecológicos e aos processos bioquímicos que conduzem a planta à produção desses metabólitos secundários.

Entre as plantas medicinais, a Menta piperita (um híbrido de $M$. viridis e $M$. aquática) apresenta óleo essencial de grande interesse econômico. A composição do seu óleo varia muito ao longo do ano e nas diversas fases de seu desenvolvimento (Corrêa Junior et al., 1994; Martins, 2002; Di Stasi et al., 2002).

O gênero Mentha pertence à família das Lamiaceas (antiga Labiatae) e compreende um número muito grande de espécies, dentre elas a Mentha piperita (ou hortelã). Essas plantas são originárias da Europa, suportam temperaturas muito baixas, mas são bem adaptadas ao clima tropical. Entretanto, temperaturas elevadas podem diminuir o rendimento de óleo essencial.

O tempo ideal para se proceder à colheita das plantas de hortelã varia conforme a época do ano, o clima da região e o destino que se dará à planta (extração de óleo essencial ou produção de material fresco). A composição do óleo essencial de menta varia em função de fatores como tipo de solo, temperatura, latitude, altitude, época de colheita e nutrição (Lima et al., 2003; Maia, 1998). Sacramento \& Campos (2002) observaram que o ponto de máxima produção de matéria seca ficou acima dos 135 dias de cultivo, indicando um comportamento característico de planta perene. Em contrapartida, Czepak (1998) observou que em colheitas entre 60 e 70 dias houve melhor rendimento de mentol cristalizável, no óleo essencial.

Quimicamente, a grande maioria dos óleos essenciais voláteis é constituída de derivados fenilpropanóides ou de terpenóides, com preponderância desses últimos. A International Standard Organization (ISO) define óleos voláteis como os produtos obtidos de partes das plantas através de destilação por arraste com vapor de água, bem como os produtos obtidos por expressão dos pericarpos de frutos cítricos. Os óleos voláteis podem ocorrer em estruturas secretoras especializadas, tais como pê- 
los glandulares, células parenquimáticas diferenciadas, canais oleíferos ou em bolsas lisígenas ou esquizolisígenas (Simões \& Spitzer, 2001).

O cultivo hidropônico pode apresentar vantagens sobre o sistema tradicional, como observado por Ocampos et al. (2002) que, ao comparar a hortelã rasteira cultivada em diferentes sistemas, observaram que o hidropônico apresentou maior rendimento (produção de biomassa e óleo essencial), sem alteração no teor do óleo essencial.

Outros resultados, como os obtidos com manjericão, permitiram a Guidotti Junior et al. (2004) concluírem que a hidroponia foi superior como técnica de cultivo. Maia et al (1999), cultivando Mentha crispa no sistema hidropônico, também observaram que a produção de folhas foi cerca de três vezes superior que a produção obtida no sistema de cultivo convencional.

A hidroponia, quando empregada em estudos de nutrição de plantas medicinais, permite estabelecer com maior segurança a importância que determinado nutriente assume na produção de biomassa ou de metabólitos.

A deficiência de alguns elementos essenciais pode estimular a formação de certas moléculas em detrimento de outras, reforçando o papel exercido pelas condições nutricionais na produção de substâncias pelo metabolismo especial ou secundário (Freire et al., 1998).

Maia (1998) observou que a omissão do nitrogênio, fósforo, potássio e cálcio reduz significativamente a produção de material verde da planta de hortelã inteira e que as proporções de limoneno, mentona, mentol e mentil acetato no óleo essencial são alteradas pelas condições de nutrição da planta.

$\mathrm{O}$ nitrogênio $(\mathrm{N})$ é um dos nutrientes absorvidos em maior quantidade pela planta e apresenta resposta positiva sobre a produção de biomassa. Isso se deve a um somatório de fatores fisiológicos, que contribuem para que a planta sintetize mais açúcares, aminoácidos e ácidos nucléicos, resultando em maior biomassa total (Maia, 1998). Entretanto, a resposta da planta a diferentes níveis de nitrogênio nem sempre é previsível no que diz respeito à produção de metabólitos especiais. Um dos fatores exógenos que podem estar diretamente relacionados à produção qualitativa e quantitativa de alguns metabólitos especiais é o fator nutricional. Porquanto, em situações de estresse nutricional, as plantas podem modular rotas biossintéticas que lhe permitirão sustentar-se no ambiente adverso (Lima et al., 2003).

Resultados com plantas de pimenta longa mostraram que variações na nutrição nítrica não se converteram em modificações na massa fresca. Apesar disso, ocorreram mudanças significativas em alguns aspectos do metabolismo primário como nas frações nitrogenadas e açúcares solúveis, sugerindo que essas alterações no metabolismo vegetal podem eventualmente se refletir no metabolismo secundário (Bucher et al., 2002).

A forma como o $\mathrm{N}$ é disponibilizado à planta também pode modificar as respostas em termos de massa fresca ou de metabólitos secundários, uma vez que, a relação $\mathrm{NO}_{3}^{-}: \mathrm{NH}_{4}^{+}$de 50:50 mostrouse prejudicial ao crescimento da hortelã (Rodriguez et al., 2002b).

Outro nutriente imprescindível ao desenvolvimento das plantas é o fósforo (P). Além do problema de ser facilmente fixado nos solos tropicais, seu deslocamento no solo é lento; portanto, sua ausência influencia diretamente o desenvolvimento das plantas, principalmente a parte aérea. O P faz parte de estruturas químicas importantes para as plantas (DNA, RNA e moléculas intermediárias do metabolismo secundário) e sua presença está relacionada com a disponibilidade de energia química (Maia, 1998).

Rodrigues et al. (2002a) observaram que a planta de hortelã responde significativamente em crescimento, ao aumento da concentração de P. Em contrapartida, outros autores (Subrahmanyam et al., 1992; Praszna \& Bernáth, 1993) observaram menores concentrações de óleo essencial em plantas de hortelã cultivadas em altos níveis de P. Além disso, foi constatado por Maia (1998) que a forma de aplicação dos adubos fosfatados afeta o rendimento da cultura.

O objetivo deste trabalho foi avaliar o efeito de soluções nutritivas com diferentes doses de N e P na produção de massa e rendimento de óleos essenciais em sistema de cultivo hidropônico.

\section{MATERIAL E MÉTODOS}

O trabalho foi conduzindo em um sistema hidropônico construído em casa de vegetação da UFRRJ, no município de Seropédica-RJ, de novembro/04 a janeiro/05. Durante a condução do experimento, a temperatura média na casa de vegetação, a solução nutritiva nos reservatórios e a intensidade da radiação fotossinteticamente ativa, foram respectivamente $37^{\circ} \mathrm{C}, 29^{\circ} \mathrm{C}$ e $876 \mu$ moles $\mathrm{cm}^{-2} \cdot \mathrm{s}^{-1}$.

O sistema hidropônico utilizado era composto por 16 canais com furos de 5 $\mathrm{cm}$ de diâmetro espaçados em $25 \mathrm{~cm}$ para a colocação das plantas, perfazendo um total de 20 furos por canal. Os 16 canais eram abastecidos por quatro reservatórios de 100 L de capacidade. Desta forma cada tanque abasteceu quatro canais, o que possibilitou a utilização de quatro tratamentos com soluções nutritivas diferentes.

A planta utilizada foi Mentha piperita, conhecida como hortelã. Estas foram cultivadas em soluções nutritivas com diferentes composições, variandose os teores de $\mathrm{N}$ e $\mathrm{P}$ conforme descrito a seguir: $(120 ; 16 ; 273 ; 53 ; 19 ; 35) ;(60$; $16 ; 271 ; 50 ; 19 ; 100) ;(120 ; 4 ; 273 ; 53$; $19 ; 41)$ e $(60 ; 4 ; 271 ; 50 ; 19 ; 106) \mathrm{mg} \mathrm{L}^{-1}$ de $\left(\mathrm{N}_{-} \mathrm{NO}_{3}^{-}, \mathrm{P}, \mathrm{K}, \mathrm{Ca}, \mathrm{Mg}, \mathrm{S}\right)$ respectivamente para os tratamentos $1 ; 2 ; 3$ e 4 . A composição dos micronutrientes foi: 300; 20; 2000; 400; 60 e $60 \mu \mathrm{g} \mathrm{L}^{-1}$ respectivamente para $\mathrm{B}, \mathrm{Cu}, \mathrm{Fe}, \mathrm{Mn}, \mathrm{Mo} \mathrm{e}$ Zn em todos tratamentos. A composição dos sais utilizados no preparo das soluções nutritivas está descrita na tabela 1 .

Em função de critérios adotados, como a utilização exclusiva de $\mathrm{N}$ na forma nítrica e as doses de $\mathrm{P}$ e $\mathrm{N}$ nos tratamentos, conseqüentemente, ocorre um desequilíbrio entre as concentrações de S nas soluções propostas. Esta variação na concentração do S poderia ser substituída pela variação na concentração de $\mathrm{Ca}$; entretanto, na literatura foram encontrados trabalhos que indicaram que o Ca, além de ser um elemento importante na fisiologia do crescimento radicular, também é mais absorvido pe- 
las plantas de hortelã que o $\mathrm{S}$, sendo a ordem de exigência dos macronutrientes na parte aérea: $\mathrm{N}>\mathrm{K}>\mathrm{Ca}>\mathrm{P}>\mathrm{Mg}>\mathrm{S}$. (Maia, 1998; Rodrigues et al., 2004).

As sementes de hortelã (Mentha piperita) foram germinadas em laboratório, acomodadas sobre espuma fenólica (previamente tratada com solução de hidróxido de sódio $0,01 \mathrm{~mol} \mathrm{~L}^{-1}$ ), umedecida com água destilada e acondicionadas em uma câmara de crescimento; quando as primeiras folhas definitivas surgiram, utilizou-se como fonte de nutrientes a solução nutritiva referente ao tratamento 2 (Tabela 1), diluída com 3 partes de água destilada, ou seja, a 1/4 de força iônica (FI).

Quando as plântulas atingiram cerca de $10 \mathrm{~cm}$ foram levadas para casa de vegetação, onde permaneceram por uma semana em fase de aclimatação; em seguida, foram transplantadas para as calhas de cultivo, sendo irrigadas com solução nutritiva a 1/4 FI na primeira semana e $1 / 2$ FI por mais uma semana (solução nutritiva referente ao tratamento 2); em seguida, as mudas foram padronizadas mediante poda, deixando-se apenas um caule com $10 \mathrm{~cm}$ de altura com 6 folhas totalmente desenvolvidas.

$\mathrm{O}$ volume de cada reservatório foi mantido em 100 L (através de reposição diária com água destilada) e o pH da solução foi corrigido para $6,0 \mathrm{com} \mathrm{KOH}$ ou $\mathrm{H}_{2} \mathrm{SO}_{4}(0,01 \mathrm{~N})$. O intervalo de irrigação foi definido calibrando-se, em 10 min aberto e 10 min fechado, para a saída de solução nutritiva. A solução nutritiva foi trocada periodicamente em intervalos de aproximadamente sete dias.

Dados de temperatura máxima e mínima dentro da casa de vegetação, volume de água consumido, volume de $\mathrm{H}_{2} \mathrm{SO}_{4}$ e $\mathrm{KOH}$ gasto para correção de $\mathrm{pH}$, temperatura da solução nutritiva, foram anotados diariamente. A densidade de fótons fotossintéticos foi medida duas vezes ao dia ( $10 \mathrm{~h}$ e $14 \mathrm{~h}$ ) em três pontos diferentes no interior e em um ponto fora da casa de vegetação. As colheitas foram realizadas aos 29; 49 e 64 DAT (dias após o início dos tratamentos).

Durante as colheitas as plantas de hortelã foram pesadas e separadas em raiz, estolão, caule e folha. Folhas foram separadas e utilizadas para a extração dos óleos essenciais. O material vegetal res-

Tabela 1. Composição de sais utilizada para o preparo das soluções nutritivas referentes aos tratamentos 1, 2, 3 e 4 (Composition of the salts used to prepare the nutrient solution from treatments 1, 2, 3 and 4). Seropédica, UFRRJ, 2005.

\begin{tabular}{|c|c|c|c|c|c|}
\hline \multirow{2}{*}{ Composição } & \multirow{3}{*}{ Categoria } & \multicolumn{4}{|c|}{ Tratamento } \\
\hline & & T1 & T2 & T3 & T4 \\
\hline Macronutriente & & \multicolumn{4}{|c|}{ g.100 L-1 } \\
\hline Nitrato de Potássio & $\mathrm{PC}^{*}$ & 70,46 & 46,15 & 70,46 & 46,15 \\
\hline Sulfato de Magnésio $7 \mathrm{H} 2 \mathrm{O}$ & $\mathrm{PA}^{* *}$ & 19,27 & 19,27 & 19,27 & 19,27 \\
\hline Nitrato de Cálcio 4H2O & PA & 23,95 & - & 23,95 & - \\
\hline MKP & $\mathrm{PC}$ & 6,96 & 6,96 & 1,74 & 1,74 \\
\hline Sulfato de Potássio & PA & - & 18,94 & 3,34 & 22,28 \\
\hline Sulfato de Cálcio & PA & 4,25 & 16,98 & 4,25 & 16,98 \\
\hline \multicolumn{2}{|l|}{ Micronutriente } & \multicolumn{4}{|c|}{ g. $1000 \mathrm{~L}^{-1}$} \\
\hline Fe-EDDHMA (Tenso Fe pó) & PC & 3,3333 & 3,3333 & 3,3333 & 3,3333 \\
\hline Ác. Bórico & PA & 0,1716 & 0,1716 & 0,1716 & 0,1716 \\
\hline Sulfato de Cobre $5 \mathrm{H} 2 \mathrm{O}$ & PA & 0,0079 & 0,0079 & 0,0079 & 0,0079 \\
\hline Sulfato de Manganês & PA & 0,1538 & 0,1538 & 0,1538 & 0,1538 \\
\hline Sulfato de Zinco $7 \mathrm{H} 2 \mathrm{O}$ & PA & 0,0264 & 0,0264 & 0,0264 & 0,0264 \\
\hline Molibdato de Sódio Anidro & PA & 0,0129 & 0,0129 & 0,0129 & 0,0129 \\
\hline
\end{tabular}

* produto comercial. ** padrão analítico (*commercial product; **analytical standard)

tante foi seco em estufa com circulação forçada de ar por $48 \mathrm{~h}$, de onde se obteve a massa seca das partes da planta.

A extração de óleos essenciais foi realizada utilizando-se o método por arraste com vapor de água, em um extrator de Clevenger (Ming et al., 1996) adaptado a um balão de $1000 \mathrm{~mL}$ e uma proveta de vidro, para alojar o material vegetal. O tempo de arraste foi definido em 30 min após o início da condensação. O hidrolato coletado foi particionado cinco vezes seguidas com $20 \mathrm{~mL}$ de diclorometano e a seguir armazenado em frascos de vidro protegidos da luz. O solvente foi eliminado por evaporação livre, sem a utilização de calor. O óleo essencial obtido a partir da massa seca das folhas foi pesado e armazenado em frascos âmbar a $-30^{\circ} \mathrm{C}$.

$\mathrm{O}$ delineamento experimental adotado foi inteiramente casualisado, em esquema fatorial 4x3 (composição da solução nutritiva $\mathrm{x}$ época de colheita) com quatro repetições. Cada repetição foi composta por cinco plantas de hortelã. Foram feitas análises de variância dos dados obtidos durante o experimento e as médias submetidas ao teste Fisher LSD a 5\%.

\section{RESULTADOS E DISCUSSÃO}

A densidade de fótons fotossintética média dentro da casa de vegetação foi de $876 \mu \mathrm{mol} \mathrm{m} \mathrm{m}^{-2} \mathrm{~s}^{-1}$. Constatou-se forte influência da cobertura de polietileno da casa de vegetação sobre a intensidade luminosa, apresentando uma redução no interior da casa de vegetação de até $40 \%$ em relação ao exterior. As temperaturas da solução nutritiva nos tanques não apresentaram variações significativas entre os tratamentos (dados não apresentados).

A média diária de reposição de água nos reservatórios durante o experimento foi de: 26,0; 19,5; 23,0 e 18,0 L de água para elevar o volume dos tanques dos tratamentos 1; 2; 3 e 4, respectivamente, a 100 L. A média da reposição de água foi estatisticamente igual para os tratamentos 1 e 3, e diferentes para os demais. Esta reposição de água está diretamente relacionada com as condições climáticas na casa de vegetação, como as altas temperaturas que, por sua vez, aumentam a evapotranspiração. Os tratamentos 1 e 3 exigiram maiores quantidades de água, provavelmente pelo maior crescimento vegetativo, influenciado pelas maiores doses de N, aumentando a evapotranspiração nesses tratamentos.

Os volumes de ácido $\left(\mathrm{H}_{2} \mathrm{SO}_{4} 0,01 \mathrm{~N}\right)$ e base $(\mathrm{KOH} 0,01 \mathrm{~N})$ gastos para efetuar a correção do $\mathrm{pH}$ da solução nutritiva nos tanques dos tratamentos $1 ; 2 ; 3$ e 4 foram respectivamente $1.501,292$; $1.127,383 ; 1.305,192$ e $1.024 ; 429 \mathrm{~mL}$. Os volumes de ácido e base necessários 


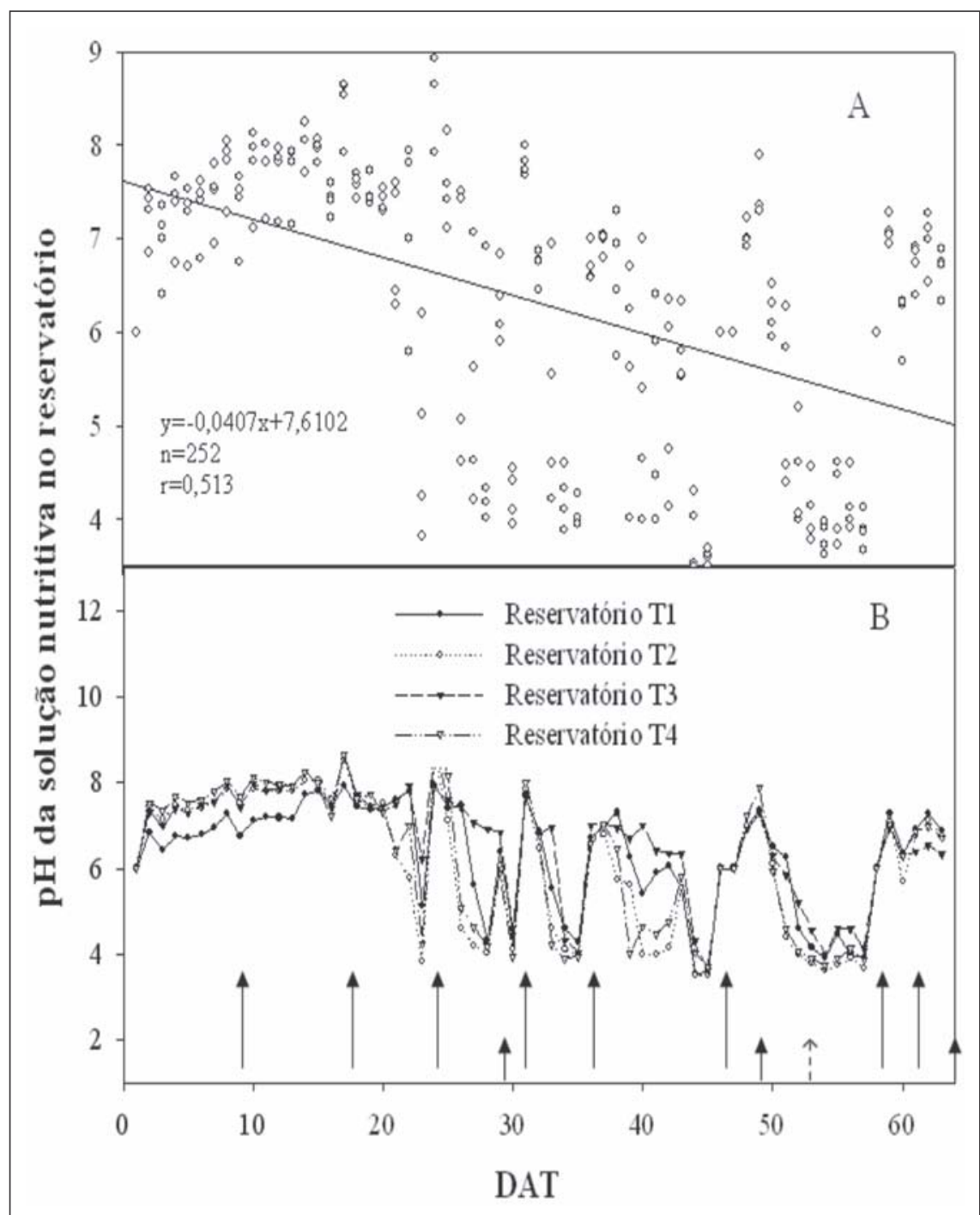

Figura 1. Regressão linear dos valores de $\mathrm{pH}$ em relação à idade da planta, com $1 \%$ de significância (A) e valor de $\mathrm{pH}$ das soluções nutritivas nos diferentes tanques no decorrer do experimento (B). Setas longas: indicam os dias de troca da solução nutritiva. Setas curtas: indicam os dias de colheita. Seta pontilhada: indica o início da floração (Linear regression from $\mathrm{pH}$ values in relation to plants's age, significantly at $1 \%$ (A) and $\mathrm{pH}$ value of the nutritive solutions in distinct tanqs during the research (B). Long arrows indicate the days when the nutritive solution was changed. Little arrows indicate the harvesting days. Dotted arrows indicate the begin of flowering). Seropédica, UFRRJ, 2005.

para o controle de $\mathrm{pH}$ da solução também sofreram influência dos tratamentos, embora os resultados não tenham sido analisados estatisticamente, pois a distribuição dos valores não permitiu a aplicação de testes estatísticos. Os tratamentos 1 e 3, principalmente o primeiro, exigiram maiores quantidades de $\mathrm{H}_{2} \mathrm{SO}_{4}$ e menores quantidades de $\mathrm{KOH}$, enquanto que os tratamentos 2 e 4 apresentaram comportamento contrário. Nos primeiros dias, após a troca da solução nutritiva, observou-se que a necessidade de ácido para a correção do $\mathrm{pH}$ era maior que no final da solução nutritiva (Figura 1B).
No transcorrer do experimento, observou-se relação negativa entre o $\mathrm{pH}$ da solução nutritiva e a idade da planta (Figura 1A). Com o crescimento há demanda crescente nutricional, o que implica no esgotamento mais acelerado dos nutrientes presentes na solução nutritiva e, conseqüentemente, na necessidade maior, por parte da planta, em realizar a extrusão de prótons, que pode ser uma resposta ao desbalanço iônico provocado pela absorção de excesso de cátions (principalmente $\mathrm{K}^{+}$), e que também favorece a absorção de $\mathrm{N}$ e $\mathrm{P}$ (Bucher et al, 2005).
Devido às variações nas doses de $\mathrm{N}$ e P nas soluções nutritivas, houve variações nas doses de S. Segundo Epstein \& Bloom (2005), a assimilação do $\mathrm{N} \mathrm{e}$ do $S$ é coordenada, principalmente, porque ambos são constituintes de aminoácidos, coenzimas e outras biomoléculas. Entretanto, a variação do $\mathrm{S}$ nas soluções nutritivas não resultou em sintomas de deficiência ou toxicidade. Resultados encontrados por Oliveira et al. (2005), mostraram que a produção de massa seca de Brachiaria brizantha não sofreu alteração entre os tratamentos com $\mathrm{N}$ na presença ou não de $\mathrm{S}$, em doses crescentes desses elementos. Os mesmos autores observaram que os tratamentos com $\mathrm{S}$ não influenciaram a absorção do $\mathrm{P}$ e do $\mathrm{N}$.

Em relação ao desenvolvimento vegetativo, as plantas de hortelã apresentaram crescimento contínuo, com ganho de massa progressivo. Aos 29 DAT as plantas apresentaram 511,0 $\mathrm{g}$ de massa fresca e 62,2 $\mathrm{g}$ de massa seca ( $\mathrm{g} / 5$ plantas); aos 49 DAT este valor dobrou e aos 64 DAT o ganho de massa fresca e seca foi três vezes superior à primeira colheita (29 DAT). Este comportamento comprova que a hortelã apresenta características de planta perene, com tendências ao ganho de peso mesmo após a floração, que ocorreu entre a segunda e a terceira colheita (Tabela 2).

O período de crescimento ideal para colheita das plantas de hortelã varia conforme seu destino, que pode ser o consumo das folhas in natura ou a produção de óleos essenciais. Neste trabalho, os resultados apontam para a possibilidade da colheita ser realizada a partir dos 29 DAT em cultivo hidropônico. Contudo, para o cultivo tradicional, Gonzaga \& Rodrigues (2006) recomendam a primeira colheita das plantas de hortelã por volta dos 120 dias de idade. Indicação semelhante foi feita por Sacramento \& Campos (2002) ao constatarem que a melhor época para colheita se dá aos 135 dias após o plantio, quando as plantas de hortelã alcançaram o ponto máximo de produção de matéria seca. Ao contrario, Czepak (1998) recomenda que as colheitas sejam realizadas, mais cedo, entre 60 e 70 dias, pois, neste caso o objetivo foi a produção de mentol cristalizável no óleo essencial. 
Estes resultados comprovam que o cultivo hidropônico favorece às plantas um desenvolvimento mais rápido, proporcionando ganho de tempo e maior produção de massa, como foi observado por Ocampos et al. (2002), que constataram que a planta de hortelã apresentou maior produção de biomassa e rendimento de óleo se comparado a outros sistemas de cultivo e Maia et al. (1999) ao obter uma produção três vezes superior ao cultivo tradicional.

Resultados semelhantes foram encontrados por Fernandes et al. (2004), que detectaram aumento superior a $40 \%$ na produção de massa fresca de plantas de manjericão cultivadas em hidroponia. Guidotti Junior et al. (2004) observaram que os melhores resultados de produção de manjericão foram obtidos em cultivo hidropônico, quando comparados ao cultivo tradicional.

Considerando a relação N/P na solução nutritiva de 7,$5 ; 3,75 ; 30$ e 15 respectivamente para os tratamentos $1 ; 2 ; 3$ e 4 , pode-se observar que a relação N/P igual a 7,5 foi a que apresentou maior produção de biomassa (Tabela 2). Em contrapartida, a solução com relação N/P igual a 15 foi a que apresentou maior rendimento de óleo essencial nas folhas (Tabela 4).

Houve interação entre as doses de $\mathrm{Ne}$ $\mathrm{P}$ das diferentes soluções nutritivas na produção de biomassa, nas três colheitas realizadas. Os tratamentos proporcionaram crescimento diferenciado, sendo o maior ganho de massa influenciado pelo tratamento 1 , que corresponde às maiores doses de $\mathrm{N}$ e $\mathrm{P}$, seguido pelo tratamento 3 com maior dose de $\mathrm{N}$ e menor de $\mathrm{P}$ (Tabela 2). Estes resultados demonstram claramente a influência positiva do $\mathrm{N}$ no desenvolvimento vegetativo da hortelã.

Resultados semelhantes foram encontrados por Oliveira et al. (2003) ao relatarem que houve aumento linear na produção de massa verde, na cultura do coentro, em função do aumento nas doses de $\mathrm{N}$ aplicado. Relatos de Abreu et al. (2002), ao trabalharem com plantas de insulina, mostraram que as mesmas responderam positivamente aos acréscimos de N, para a produção de biomassa. Estes autores constataram também efeito interativo entre doses de $\mathrm{N}$ e $\mathrm{P}$, que em maiores doses, proporcionaram maior produção de matéria seca foliar.

Tabela 2. Massa fresca e seca total de plantas de Mentha piperita (hortelã) cultivadas em soluções nutritivas com diferentes teores de N e P, colhidas aos 29, 49 e 64 dias após a aplicação dos tratamentos (DAT) (Fresh and dry total matter of Mentha piperita plants, cultivated in nutrient solution with distinct contents of $\mathrm{N}$ and P, harvested at 29, 49 and 64 days after treatment (DAT)). Seropédica, UFRRJ, 2005.

\begin{tabular}{|c|c|c|c|c|c|c|}
\hline \multirow{2}{*}{ Tratamento - } & \multicolumn{2}{|c|}{${ }^{*}$ Dose } & \multicolumn{4}{|c|}{ Massa fresca (g/5 plantas) } \\
\hline & $\mathrm{N}-\mathrm{NO}_{3}^{-}$ & $\mathbf{P}$ & 29 DAT & 49 DAT & 64 DAT & Média \\
\hline $\mathrm{T1}$ & 120 & 16 & $554,1 \mathrm{aC}$ & $1.572,1 \mathrm{aB}$ & $2.012,8 \mathrm{aA}$ & $1.379,7 \mathrm{a}$ \\
\hline T2 & 60 & 16 & $456,8 \mathrm{bC}$ & $1.119,6 \mathrm{cB}$ & $1.343,9 \mathrm{cA}$ & $973,4 \mathrm{c}$ \\
\hline T3 & 120 & 4 & $575,4 \mathrm{aC}$ & $1.245,0 \mathrm{bB}$ & $1.652,2 \mathrm{bA}$ & $1.157,5 b$ \\
\hline T4 & 60 & 4 & $457,7 \mathrm{bC}$ & $1.004,2 \mathrm{cB}$ & $1.355,3 \mathrm{cA}$ & $939,1 \mathrm{c}$ \\
\hline Média & & & $511,0 \mathrm{C}$ & 1235,2 B & $1591,1 \mathrm{~A}$ & $1.112,4$ \\
\hline \multirow{2}{*}{ Tratamento- } & \multicolumn{2}{|c|}{${ }^{*}$ Dose } & \multicolumn{4}{|c|}{ Massa seca (g/5 plantas) } \\
\hline & $\mathrm{N}-\mathrm{NO}_{3}^{-}$ & $\mathbf{P}$ & 29 DAT & 49 DAT & 64 DAT & Média \\
\hline T1 & 120 & 16 & $64,1 \mathrm{abC}$ & $227,3 \mathrm{aB}$ & 307,4 aA & 199,6 a \\
\hline T2 & 60 & 16 & $53,5 \mathrm{bC}$ & $164,5 \mathrm{bB}$ & 218,3 bA & $145,4 \mathrm{c}$ \\
\hline T3 & 120 & 4 & 71,7 aC & 157,1 bB & 223,6 bA & $150,8 \mathrm{~b}$ \\
\hline T4 & 60 & 4 & $59,8 \quad b C$ & $145,5 \mathrm{bB}$ & 207,6 bA & $137,6 \mathrm{c}$ \\
\hline Média & & & $62,2 \quad C$ & $173,6 \quad$ B & 239,2 A & 158,4 \\
\hline
\end{tabular}

* mg. $\mathrm{L}^{-1}$ de $\mathrm{N}$ ou $\mathrm{P}$ na solução nutritiva. Letras maiúsculas iguais na mesma linha e minúsculas iguais na mesma coluna não diferem significativamente pelo teste de Fisher LSD a 5\% de probabilidade. ( ${ }^{*} \mathrm{mg} \mathrm{L} \mathrm{L}^{-1}$ of $\mathrm{N}$ or $\mathrm{P}$ in the nutritive solution. Same letters maiúsculas in the line and minúsculas in the column did not differ significantly through the Fisher LSD test, 5\% probability).

Como pode ser observado da tabela 2 , a maior produção encontrada aos 29 DAT ocorreu nas condições dos tratamentos 1 e 3 e aos 49 e 64 DAT no tratamento 1 , o que demonstra um efeito interativo entre as maiores doses de $\mathrm{N}$ e $\mathrm{P}$ sobre a produção de biomassa, a partir dos 49 DAT.

Ao comparar os efeitos das doses de $\mathrm{N}$ e P, observou-se que o P atuou limitando a produção de biomassa da parte aérea nos tratamentos 3 e 4 (com menores doses de P) e, ao mesmo tempo, estimulou o aumento de biomassa nas raízes, como pode ser observado na tabela 3. Resultados semelhantes foram encontrados por Rodrigues et al (2004) que observaram maior produção de massa na parte aérea, em função dos maiores níveis de $\mathrm{P}$ na solução nutritiva. Em contrapartida, esses autores não observaram aumento na produção de massa nas raízes, quando cultivadas nas soluções nutritivas com menores doses de P.

O fato observado está associado à mobilidade do P na planta. Como o deslocamento do $\mathrm{P}$ na planta ocorre via simplástica, ao contrário do $\mathrm{N}$ e do $\mathrm{K}$, que ocorrem tanto via simplástica como apoplástica, há um desbalanço entre os níveis de $\mathrm{N}$ e $\mathrm{P}$ na parte aérea. Dessa forma, os menores teores de $\mathrm{P}$ prejudicam o crescimento da parte aérea, enquanto na raiz sua presença atua de forma positiva para o ganho de massa.
Epstein \& Bloom (2005) relataram que raízes submetidas a baixos níveis de $\mathrm{P}$ produziram maior quantidade de raízes laterais e pelos absorventes, formando o que se chama de "root hairs", o que conseqüentemente leva ao aumento de biomassa neste órgão.

Como o desenvolvimento da parte aérea é fundamental para a captação de energia luminosa e, sabendo-se que a raiz atua como um dreno na planta, observa-se na tabela 3 que no tratamento 1 , onde houve maior ganho de massa na parte aérea, houve efetivamente maior produção total de massa aos 49 e 64 DAT (Tabela 2).

Os tratamentos 2 e 4, com menores doses de $\mathrm{N}$, apresentaram maiores rendimentos de óleo essencial e produção de óleo essencial; contudo, detectou-se efeito interativo com as épocas de colheita e os tratamentos. Entre as colheitas (29; 49 e 64 DAT) não foram observadas diferenças nas produções (gramas/5 plantas) de óleo essencial (Tabela 4).

Dragar \& Menary (1995) observaram diminuição no rendimento de óleo essencial em Olearia phlogopappa em baixos níveis de fósforo. Por outro lado, outros autores (Kothari et al., 1987; Praszna \& Bernáth, 1993) observaram menores concentrações de óleo essencial em plantas de hortelã cultivada em altos níveis de $\mathrm{P}$. 
Tabela 3. Massa fresca e seca de raiz, estolão, caule e folha de plantas de Mentha piperita (hortelã) cultivadas em soluções nutritivas com diferentes teores de $\mathrm{N}$ e P, colhidas aos 29, 49 e 64 dias após a aplicação dos tratamentos (DAT) (Fresh and dry matter of roots, stolon, stem and leaves of mint plants, cultivated in a nutritive solution with distinct contents of $\mathrm{N}$ and P, harvested 29, 49 and 64 days after treatment (DAT)). Seropédica, UFRRJ, 2005.

\begin{tabular}{|c|c|c|c|c|c|c|c|}
\hline \multirow{2}{*}{ Coleta } & \multirow{2}{*}{ Tratamento } & \multicolumn{2}{|c|}{${ }^{*}$ Dose } & \multicolumn{4}{|c|}{ Massa fresca (g/5 plantas) } \\
\hline & & $\mathrm{N}-\mathrm{NO}_{3}^{-}$ & $\mathbf{P}$ & Raiz & Estolão & Caule & Folha \\
\hline \multirow{5}{*}{$\begin{array}{l}\text { 合 } \\
\text { 令 }\end{array}$} & T1 & 120 & 16 & $172,2 \mathrm{~b}$ & $90,1 \mathrm{~b}$ & $137,6 \mathrm{a}$ & $154,3 \mathrm{a}$ \\
\hline & $\mathrm{T} 2$ & 60 & 16 & 178,2 b & 76,4 bc & $88,5 \mathrm{~b}$ & $113,7 b$ \\
\hline & T3 & 120 & 4 & $196,2 a$ & $115,4 \mathrm{a}$ & $126,0 \mathrm{a}$ & 137,9 a \\
\hline & $\mathrm{T} 4$ & 60 & 4 & $197,5 a$ & $72,8 \mathrm{c}$ & $84,3 \mathrm{~b}$ & $103,1 \mathrm{~b}$ \\
\hline & Média & & & $186,0 \mathrm{~A}$ & 88,6 B & 109,1 B & $127,2 \mathrm{~A}$ \\
\hline \multirow{5}{*}{$\begin{array}{l}\text { \& } \\
8 \\
8 \\
8\end{array}$} & T1 & 120 & 16 & $407,4 \mathrm{a}$ & $331,1 \mathrm{a}$ & 359,3 a & 474,3 a \\
\hline & $\mathrm{T} 2$ & 60 & 16 & 402,6 a & $243,0 \mathrm{~b}$ & $175,8 \mathrm{bc}$ & $298,2 \mathrm{~b}$ \\
\hline & T3 & 120 & 4 & 460,9 a & $226,2 \mathrm{~b}$ & $245,9 \mathrm{~b}$ & $311,9 \mathrm{~b}$ \\
\hline & $\mathrm{T} 4$ & 60 & 4 & $319,6 \mathrm{~b}$ & $258,8 \mathrm{~b}$ & $163,8 \mathrm{c}$ & $262,0 \mathrm{~b}$ \\
\hline & Média & & & $397,6 \mathrm{~A}$ & 264,8 B & $236,6 \mathrm{C}$ & $336,6 \mathrm{AB}$ \\
\hline \multirow{6}{*}{$\begin{array}{l}\text { E } \\
\text { ¿ } \\
\text { to }\end{array}$} & T1 & 120 & 16 & $567,3 \mathrm{~b}$ & 379,1 a & 439,9 a & 626,5 a \\
\hline & $\mathrm{T} 2$ & 60 & 16 & $439,5 \mathrm{c}$ & $300,3 \mathrm{~b}$ & $234,2 \mathrm{c}$ & $369,9 \mathrm{~b}$ \\
\hline & T3 & 120 & 4 & 620,4 a & $304,6 \mathrm{~b}$ & $352,8 \mathrm{~b}$ & $374,3 \mathrm{~b}$ \\
\hline & $\mathrm{T} 4$ & 60 & 4 & $532,9 \mathrm{~b}$ & $325,3 \mathrm{~b}$ & 197,6 c & $299,5 \mathrm{c}$ \\
\hline & Média & & & $540,0 \mathrm{~A}$ & $327,4 \mathrm{C}$ & $306,1 \mathrm{C}$ & $417,6 \mathrm{~B}$ \\
\hline & & & & \multicolumn{4}{|c|}{ Massa seca (g/5 plantas) } \\
\hline \multirow{5}{*}{$\begin{array}{l}\text { 京 } \\
\text { 令 }\end{array}$} & $\mathrm{T} 1$ & 120 & 16 & $8,5 \mathrm{~b}$ & $10,3 \mathrm{~b}$ & $18,1 \mathrm{a}$ & 27,2 a \\
\hline & $\mathrm{T} 2$ & 60 & 16 & $10,5 \mathrm{~b}$ & $9,0 \mathrm{~b}$ & $13,1 \mathrm{~b}$ & 20,8 b \\
\hline & T3 & 120 & 4 & $10,7 b$ & 13,9 a & 17,1 a & 29,9 a \\
\hline & $\mathrm{T} 4$ & 60 & 4 & $13,0 \mathrm{a}$ & $9,4 \mathrm{~b}$ & $13,7 \mathrm{~b}$ & $23,6 \mathrm{~b}$ \\
\hline & Média & & & $10,7 \mathrm{C}$ & $10,7 \mathrm{C}$ & $15,5 \mathrm{~B}$ & $25,4 \mathrm{~A}$ \\
\hline \multirow{5}{*}{$\begin{array}{l}\text { \& } \\
\text { 品 } \\
\text { g }\end{array}$} & T1 & 120 & 16 & $23,6 \mathrm{~b}$ & 42,3 a & 70,5 a & 90,9 a \\
\hline & $\mathrm{T} 2$ & 60 & 16 & 24,6 a & 34,5 b & $39,9 \mathrm{c}$ & 65,5 b \\
\hline & T3 & 120 & 4 & 26,7 a & $26,1 \mathrm{c}$ & $46,4 \mathrm{~b}$ & $57,9 \mathrm{c}$ \\
\hline & $\mathrm{T} 4$ & 60 & 4 & $21,6 \mathrm{~b}$ & 37,2 b & $36,1 \mathrm{~d}$ & $50,6 \mathrm{~d}$ \\
\hline & Média & & & $24,1 \mathrm{D}$ & $35,1 \mathrm{C}$ & 48,2 B & $66,2 \mathrm{~A}$ \\
\hline \multirow{5}{*}{$\begin{array}{l}\text { 衣 } \\
\text { d }\end{array}$} & T1 & 120 & 16 & $30,5 \mathrm{~b}$ & $50,1 \mathrm{a}$ & 103,8 a & 122,9 a \\
\hline & $\mathrm{T} 2$ & 60 & 16 & $29,5 \mathrm{~b}$ & $46,3 \mathrm{~b}$ & $61,3 \mathrm{c}$ & 81,2 b \\
\hline & T3 & 120 & 4 & 37,7 a & $38,2 \mathrm{c}$ & $74,0 \mathrm{~b}$ & $73,8 \mathrm{c}$ \\
\hline & $\mathrm{T} 4$ & 60 & 4 & 37,8 a & 56,1 a & $47,9 \mathrm{~d}$ & $65,8 \mathrm{~d}$ \\
\hline & Média & & & $33,9 \mathrm{D}$ & $47,7 \mathrm{C}$ & $71,8 \mathrm{~B}$ & $85,9 \mathrm{~A}$ \\
\hline
\end{tabular}

* mg. $\mathrm{L}^{-1}$ de $\mathrm{N}$ ou $\mathrm{P}$ na solução nutritiva. Letras maiúsculas iguais na mesma linha e minúsculas iguais na mesma coluna não diferem significativamente (Fisher LSD 5\%).

Esperava-se que com o aumento da produção de massa na parte aérea houvesse maior produção de óleo nas plantas; entretanto, como o rendimento ao longo das três colheitas diminuiu de $1,47 \%$ aos 29 DAT para $0,48 \%$ aos 64 DAT, a média de produção de óleo essencial foi de 0,39 $\mathrm{g} / 5$ plantas (Tabela 4).

Aos 29 DAT, as plantas submetidas a maiores doses de $\mathrm{N}$ (tratamentos 1 e 3 ) apresentaram menor rendimento de óleo. Este comportamento se manteve com pequenas variações aos 49 DAT (Tabela 4). Não se observou influência significativa das doses de P sobre o rendimento de óleo es- va no rendimento do óleo, mostrando que a melhor época de colheita neste sistema ocorre por volta dos 29 DAT, pois os gastos com manutenção dos equipamentos, insumos e mão-de-obra são fatores que oneram os custos de produção.

O rendimento do óleo mostrou-se indiretamente relacionado com a produção de massa seca (Figura 2), o que provavelmente ocorreu pelo fato do vegetal produzir maior número de tricomas glandulares na planta ainda jovem, decrescendo no período de floração e novamente aumentando após este período, conforme relatos de diversos autores (Turner et al., 2000; Mcconkey et al., 2000; Martins, 2002).

Tanto o N quanto o P têm importância sobre o crescimento vegetativo da planta, pois estão diretamente relacionados a diversos eventos metabólicos ou fazendo parte de estruturas químicas na planta; por isso, a disponibilidade desses nutrientes em condições de serem absorvidos e assimilados promove o crescimento adequado da planta.

Contudo, observa-se que o tratamento 1 , com maiores doses de $\mathrm{N}$ e $\mathrm{P}$, embora tenha proporcionado melhor desenvolvimento vegetativo da parte aérea (Tabela 2), não foi o que proporcionou maior rendimento de óleo essencial (Tabela 4). A ativação das vias metabólicas especiais pode estar relacionada com fatores externos, sendo a disponibilidade de nutrientes uma delas. No início do crescimento a disputa pelo nutriente é menor, mas com o crescimento da planta, o conteúdo de $\mathrm{N}$ e $\mathrm{P}$ pode ter promovido competição entre as plantas e levado à diminuição no rendimento de óleo ao longo das colheitas (Tabela 4). Além disto, um fator não nutricional pode estar associado à diminuição do rendimento de óleo essencial ao longo do experimento, como a maturação das folhas e as condições ambientais. Segundo Martins (2002), ocorre diminuição na produção de tricomas glandulares em consequiência da maturação das folhas e isto seria responsável pela diminuição na produção de óleos voláteis.

Após a produção dos tricomas glandulares, são necessários apenas 30 horas para o completo enchimento do compartimento de armazenamento das 
Tabela 4. Rendimento e produção de óleo essencial em folhas de plantas de Hortelã cultivadas em soluções nutritivas com diferentes teores de N e P, colhidas aos 29, 49 e 64 dias após a aplicação dos tratamentos (DAT) (Yield and essential oil production of mint leaves cultivated under nutritive solution with different contents of $\mathrm{N}$ and P, harvested at 29, 49 and 64 days after application of the treatments (DAT)). Seropédica, UFRRJ, 2005.

\begin{tabular}{|c|c|c|c|c|c|c|c|c|c|c|}
\hline \multirow{3}{*}{ * Dose } & \multirow{2}{*}{\multicolumn{2}{|c|}{ * Dose }} & \multicolumn{4}{|c|}{ ** Rendimento (\%) } & \multicolumn{4}{|c|}{ *** Produção (g/5 plantas) } \\
\hline & & & \multicolumn{3}{|c|}{ DAT } & \multirow{2}{*}{ Média } & \multicolumn{3}{|c|}{ DAT } & \multirow{2}{*}{ Média } \\
\hline & $\mathrm{NO}_{3}^{-}$ & $\mathbf{P}$ & 29 & 49 & 64 & & 29 & 49 & 64 & \\
\hline $\mathrm{T} 1$ & 120 & 16 & $1,09 \mathrm{bA}$ & $0,51 \mathrm{bB}$ & $0,32 \quad b C$ & $0,64 \mathrm{~b}$ & $0,25 \mathrm{bB}$ & $0,46 \mathrm{aA}$ & $0,39 \mathrm{aB}$ & $0,37 \mathrm{~b}$ \\
\hline T2 & 60 & 16 & 1,89 aA & $0,65 \mathrm{abB}$ & $0,52 a b c$ & $1,02 a$ & 0,46 aA & $0,43 a A$ & 0,42 aA & $0,44 a$ \\
\hline T3 & 120 & 4 & $1,05 \mathrm{bA}$ & $0,51 \mathrm{bB}$ & $0,45 a b c$ & $0,67 \mathrm{~b}$ & $0,30 \mathrm{bA}$ & $0,29 \mathrm{bA}$ & 0,33 aA & $0,31 \mathrm{~b}$ \\
\hline T4 & 60 & 4 & 1,87 aA & $0,75 \mathrm{aB}$ & $0,63 \mathrm{aC}$ & $1,08 a$ & $0,56 \mathrm{aA}$ & $0,38 \mathrm{aB}$ & $0,39 \mathrm{aB}$ & $0,44 a$ \\
\hline Média & & & $1,47 \mathrm{~A}$ & $0,60 \quad$ B & $0,48 \quad C$ & 0,85 & $0,39 \mathrm{~A}$ & $0,39 \mathrm{~A}$ & $0,38 \quad A$ & 0,39 \\
\hline
\end{tabular}

* mg. $\mathrm{L}^{-1}$ de $\mathrm{N}$ ou $\mathrm{P}$ na solução nutritiva. ** Percentual calculado sobre o peso seco de folhas. *** Produção calculada sobre o peso seco de folhas de 5 plantas. Letras maiúsculas iguais na mesma linha e minúsculas iguais na mesma coluna não diferem significativamente (Fisher LSD 5\%) (*mg L ${ }^{-1}$ of $\mathrm{N}$ or P in the nutritive solution. **Calculated percentage of dry matter of leaves. ***Evaluated yield from dry weight of leaves from 5 plants. Head same letters in the line and little letters in the column did not differ significantly (Fisher LSD 5\%)).

glândulas com óleo essencial. A partir desse momento, condições ambientais como vento, radiação solar e temperatura, poderiam favorecer o extravasamento desse material estocado (Mcconkey et al., 2000; Turner et al., 2000).

Neste trabalho, a produção de massa na parte aérea da hortelã foi estimulada no tratamento 1 , com maiores doses de $\mathrm{N}$ e $\mathrm{P}$; os tratamentos 3 e 4 com menores dose de $\mathrm{P}$ estimularam maior produção de massa nas raízes e limitaram a produção de massa nas folhas. Os resultados encontrados mostraram que para a produção de óleos essenciais em plantas de hortelã, as soluções nutritivas devem ter uma relação N/P igual a 15 , associada a teores de $\mathrm{N}$ que não promovam o crescimento exagerado da planta, neste caso, o tratamento 4 (com colheita aos 29 DAT). Para a produção de hortelã in natura, deve ser fornecida às plantas solução nutritiva com relação $\mathrm{N} / \mathrm{P}$ igual a 7,5, associada a teores de $\mathrm{N}$ que promovam o maior desenvolvimento da parte aérea; portanto, neste caso, o tratamento 1 é indicado para o cultivo hidropônico, com colheitas entre 49 e 64 DAT.

\section{AGRADECIMENTOS}

À FAPERJ, CNPq e CAPES pela bolsas de estudos e pelos recursos financeiros que permitiram a realização desse trabalho, bem como ao CPGA-CS/ UFRRJ.

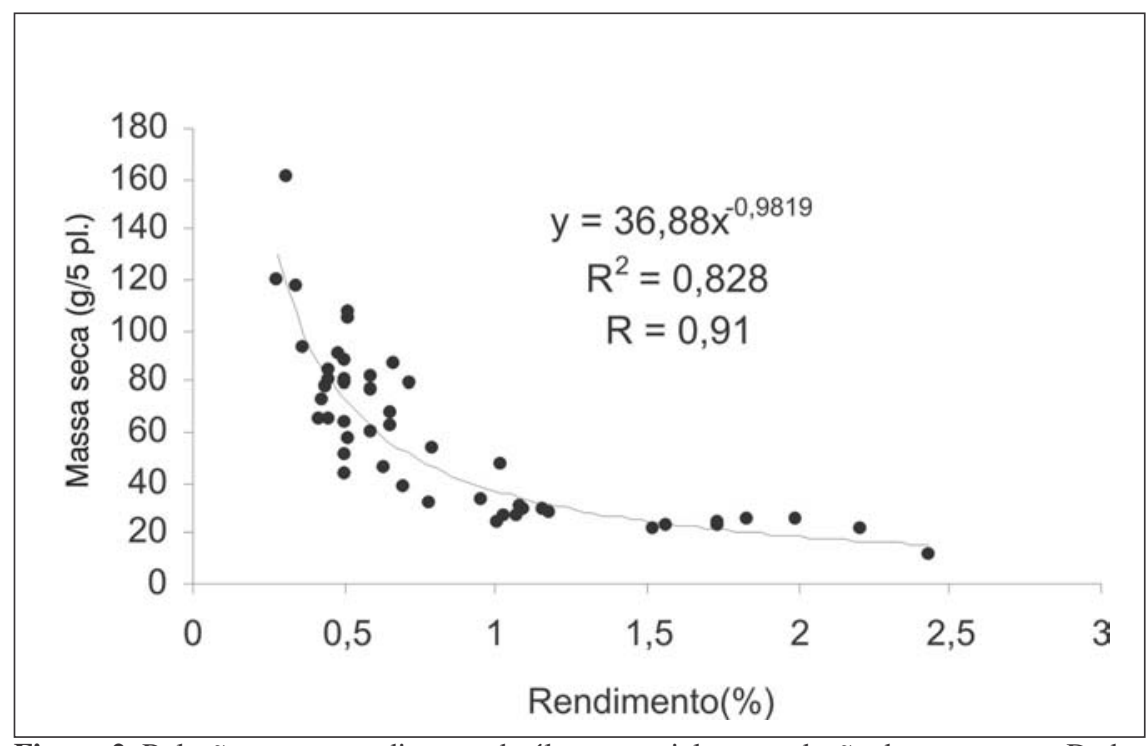

Figura 2. Relação entre o rendimento de óleo essencial e a produção de massa seca. Dados das três colheitas (Relation beetwen the yield of essential oil and the production of dry matter. Data from three harvests). Seropédica, UFRRJ, 2005.

\section{REFERÊNCIAS}

ABREU IN; PINTO JEBP; FURTINI NETO AE; BERTOLUCCI SKV; LADEIRA A; GEROMEL C. 2002. Nitrogênio e fósforo na produção vegetal e na indução de mucilagem em plantas de insulina. Horticultura Brasileira 20: 536-540.

BUCHER CA; MATIA GCSS; NICOMEDES JUNIOR J; ARAÚJO OJL; STARK EMLM; FERNANDES MS; SOUZA SR. 2002. Frações nitrogenadas e açúcares solúveis nas partes de pimenta longa cultivada sob duas doses de N-NO3-. In: FERTBIO 2002. Resumos... Rio de Janeiro: SBCS. (CD-ROM).

BUCHER CA; SOUZA SR; FERNANDES MS 2005. Effects of fusicoccin and vanadate on proton extrusion and potassium uptake by rice. Journal of Plant Nutrition 28: 1-18.
CORRÊA JÚNIOR C. 1994. Cultivo de plantas medicinais, condimentares e aromáticas. Jaboticabal: FUNEP. 162 p.

CZEPAK MP. 1998. Produção de óleo bruto e mentol cristalizável em oito freqüências de colheta da menta (mentha arvensis L.). In MING LC. (ed). Plantas medicinais aromática e condimentares: avanços na pesquisa agronômica. Botucatu: UNESP. p. 53 -80.

DI STASI LC. 1996. Plantas Medicinais: arte e ciência. Um guia de estudo interdisciplinar. São Paulo: UNESP 230p.

DI STASI LC; HIRUMA-LIMA CA. 2002. Plantas medicinais na Amazônia e na mata atlântica. São Paulo: UNESP 604p.

DRAGAR VA; MENARY RC. 1995. Mineral nutrition of Olearia phlogopappa: effect on growth, essential oil yield, and composition. Commun. Soil Sci. Plant Anal. 26:1299-1313. 
EPSTEIN E; BLOOM AJ. 2005. Mineral nutrition of plants: principles and perspectives. Sunderland, Massachusetts: Sinauer Associates, Inc. 400p.

FERNANDES PC; FACANALI R; TEIXEIRA JPF; FURLANI PR; MARQUES MOM. 2004 Cultivo de manjericão em hidroponia e em diferentes substratos sob ambiente protegido. Horticultura Brasileira 22: 260-264.

FREIRE MFI; SOUZA SR; BERBARA RLL; ABREU HS. 1998. Vernonia scorpioides (Lam.) Pers. Asteraceae - determinação de fatores nutricionais relacionados a produção de principio ativo. Floresta e Ambiente 5: 35-138.

GONZAGA DSOM; RODRIGUES VG. 2006. Hortelã-pimenta: Mentha piperita L. Folder 09, Série Plantas Medicinais. EMBRAPA. Disponível em: <http://www.cpafro.embrapa.br/ embrapa/infotec/hortela_pim.PDF $>$. Acessado em 10 janeiro de 2006.

GUIDOTTI JUNIOR W; TEIXEIRA NT; ALMEIDA FD; JANINI MJDM. 2004. Cultivo orgânico, mineral, organo-mineral e hidropônico do Manjericão. In: FERTBIO 2004. Resumos... Lages: SBCS (CD-ROM).

KOTHARI SK; SINGH V; SINGH K. 1987. Effect of rates and method of $\mathrm{P}$ application on herb and oil yields and nutrient concentrations in Japanese mint (Mentha arvensis L.). Journal of Agricultural Science 108: 691-693.

LIMA HRP; KAPLAN MAC; CRUZ AVM. 2003. Influencia dos fatores abióticos na produção e variabilidade de terpenóides em plantas. Floresta e Ambiente 10: 71-77.

MAIA NB. 1998. Efeito da nutrição mineral na qualidade do óleo essencial da menta (Mentha arvensis) Cultivada em solução nutritiva. In MING LC. Plantas medicinais aromática e condimentares: avanços na pesquisa agronômica. Botucatu: UNESP. p. 81-96.

MAIA NB; CARMELLO QAC; MARQUES MOM. 1999. Sistema automático de fornecimento de solução nutritiva para cultivo hidropônico de plantas em vasos. Sci. agric. 56: $103-110$
MARTINS MBG. 2002. Estudos de Microscopia óptica e de microscopia eletrônica de varredura em folhas de Mentha spicata e de Mentha spicata $X$ suaveolens (Lamiaceae). Bragantia 61: 205-218.

MCCONKEY ME; GERSHENZON J; CROTEAU RB. 2000. Developmental regulation of monoterpene biosynthesis in the glandular trichomes of peppermint. Plant Physiology 122: 215-223.

MING LC; FIGUEIREDO RO; MACHADO SR; ANDRADE RMC. 1996. Yield of essential oil of and citral content in different parts of lemongrass leaves (Cymbopogon citratus (D.C.) Stapf.) Poaceae. Acta Horticulturae 426: 555-559.

OCAMPOS RK; LAURA VA; CHAVES FCM 2002. Efeito de diferentes formas de adubação em hortelã rasteira: biomassa e teor de óleo essencial. In: CONGRESSO BRASILEIRO DE OLERICULTURA, 42. Resumos... Uberlândia: SOB (CD-ROM).

OLIVEIRA AP; PAIVA SOBRINHO S; BARBOSA JKA; RAMALHO CI; OLIVEIRA ALP. 2003. Rendimento de coentro cultivado com doses crescentes de N. Horticultura Brasileira 21: 81-83.

OLIVEIRA PP; TRIVELIN PCO; OLIVEIRA WS; CORSI M. 2005. Fertilização com N e S na recuperação de pastagem de Brachiaria brizantha cv. Marandu em neossolo quartzarênico. R. Bras. Zootec. 34: 1121-1129.

PRASZNA L; BERNÁTH J. 1993. Correlations between the limited level of nutrition and essential oil production of peppermint. Acta Horticulture 344: 278-289.

RODRIGUES CR; FAQUIN V; PINTO JEBP; NEVES OSC. 2002a. Efeito de concentrações de P na solução nutritiva sobre o crescimento da menta (Mentha piperita L.). In: CONGRESSO BRASILEIRO DE OLERICULTURA, 42. Resumos... Uberlândia: SOB (CD-ROM).
RODRIGUES CR; FAQUIN V; TREVISAN D; PINTO JEBP; BERTOLUCCI SKV; RODRIGUES TM. 2004. Nutrição mineral, crescimento e teor de óleo essencial da menta em solução nutritiva sob diferentes concentrações de fósforo e épocas de coleta. Horticultura Brasileira 22: 573-578.

RODRIGUES CR; FAQUIN V; PINTO JEBP; NEVES OSC. 2002b. Efeito da relação $\mathrm{NO}_{3}^{-}$ : $\mathrm{NH}_{4}^{+} \mathrm{e}$ concentrações de $\mathrm{K}$ na solução nutritiva sobre o crescimento da menta (Mentha piperita L.). In: CONGRESSO BRASILEIRO DE OLERICULTURA, 42. Resumos... Uberlândia: SOB (CD-ROM).

SACRAMENTO LVS; CAMPOS MJB. 2002. Cultivo de hortelã: produção de matéria seca e marcha de absorção de cálcio. In: CONGRESSO BRASILEIRO DE OLERICULTURA, 42. Resumos... Uberlândia: SOB (CD-ROM).

SIMÕES CMO; SPITZER V. 2001. Óleos Voláteis. In: SIMÕES CMO et al.(eds.). Farmacognosia: da planta ao medicamento. Porto Alegre/Florianópolis: Ed.Universidade/ UFRGS/Ed.UFSC. p. 397-425.

SUBRAHMANYAM K; NAIR AK; CHATTOPADHYAY A; SINGH DV. 1992. Evaluation of ammonium polyphosphate as phosphorus source in Japanese mint (Mentha arvensis subsp haplocalyx var piperascens). Indian Journal of Agricultural Sciences 62: 554-556.

TURNER GW; GERSHENZON J; CROTEAU RB. 2000. Distribution of peltate glandular trichomes on developing leaves of peppermint. Plant Physiology 124: 655-663. 